\title{
KJCCM
}

Korean J Crit Care Med

2016 August 31(3):263 / http://dx.doi.org/10.4266/kjccm.2016.31.2.129.e01

ISSN 2383-4870 (Print) · ISSN 2383-4889 (Online)

\section{Primary Invasive Intestinal Aspergillosis in a Non-Severely Immunocompromised Patient}

\author{
Eunmi Gil, M.D. ${ }^{1}$, Tae Sun Ha, M.D. ${ }^{1}$, Gee Young Suh, M.D., Ph.D. ${ }^{1,2}$, Chi Ryang Chung, M.D. ${ }^{1}$, \\ and Chi-Min Park, M.D., Ph.D. ${ }^{1,3}$
}

${ }^{1}$ Department of Critical Care Medicine, ${ }^{2}$ Division of Pulmonary and Critical Care Medicine, Department of Medicine, ${ }^{3}$ Department of Surgery, Samsung Medical Center, Sungkyunkwan University School of Medicine, Seoul, Korea

We found an error in this article. The Fig. 1A should be corrected as following:

In this article, on page 130, Fig. 1A has an error. Fig. 1A was upside down.

We present the correct figure as below:

Before correction

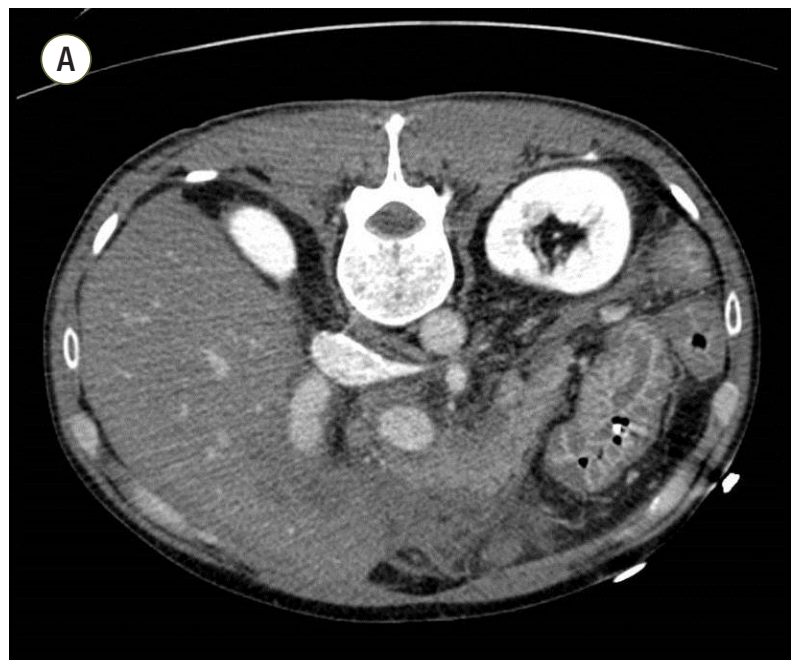

After correction

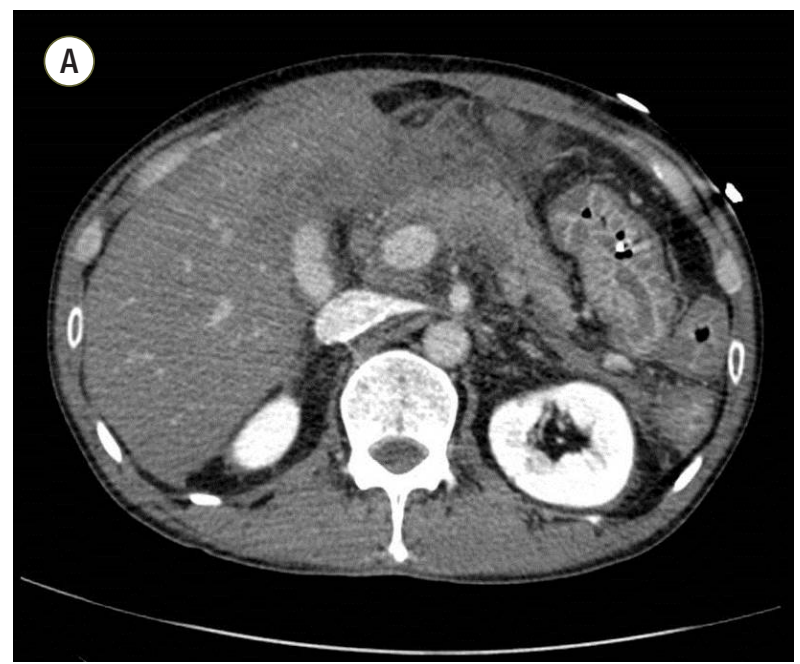

We apologize for any inconvenience that may have caused. 